\title{
Health Equity Among Black Women in the United States
}

\author{
Juanita J. Chinn, $\mathrm{PhD},{ }^{1}$ Iman K. Martin, $\mathrm{PhD}, \mathrm{MPH}, \mathrm{MSc}^{2, *}$ and Nicole Redmond, MD, PhD, MPH, FACP ${ }^{3, *}$
}

\begin{abstract}
Black women in the United States have experienced substantial improvements in health during the last century, yet health disparities persist. These health disparities are in large part a reflection of the inequalities experienced by Black women on a host of social and economic measures. In this paper, we examine the structural contributors to social and economic conditions that create the landscape for persistent health inequities among Black women. Demographic measures related to the health status and health (in)equity of Black women are reviewed. Current rates of specific physical and mental health outcomes are examined in more depth, including maternal mortality and chronic conditions associated with maternal morbidity. We conclude by highlighting the necessity of social and economic equity among Black women for health equity to be achieved.
\end{abstract}

Keywords: Black women, health equity, maternal mortality, race/ethnicity, social determinants of health

B LACK WOMEN IN the United States experienced substantial improvements in health during the last century, yet health disparities persist. Black women continue to experience excess mortality relative to other U.S. women, including-despite overall improvements among Black women-shorter life expectancies ${ }^{1}$ and higher rates of maternal mortality. ${ }^{2}$ Moreover, Black women are disproportionately burdened by chronic conditions, such as anemia, cardiovascular disease (CVD), and obesity. Health outcomes do not occur independent of the social conditions in which they exist. The higher burden of these chronic conditions reflects the structural inequities within and outside the health system that Black women experience throughout the life course and contributes to the current crisis of maternal morbidity and mortality. The health inequities experienced by Black women are not merely a cross section of time or the result of a singular incident.

\section{Historical Context for the Current Health Experience of Black Women}

Race and ethnicity are sociocultural constructs that reflect common geographic origins, cultures, and social histories of groups that are defined by societies in time-dependent contexts. ${ }^{3-6}$ Given the social construction of race and ethnicity, racial groups and identity are fluid; they can, and do, change over time and vary across place. ${ }^{7}$

No discussion of health equity among Black women is complete unless it considers the impacts of institutional- and individual-level forms of racism and discrimination against Black people. Nor is a review of health equity among Black women complete without an understanding of the intersectionality of gender and race and the historical contexts that have accumulated to influence Black women's health in the United States.

\footnotetext{
${ }^{1}$ Population Dynamics Branch, Division of Extramural Research, Eunice Kennedy Shriver National Institute of Child Health and Human Development, Bethesda, Maryland, USA.

${ }^{2}$ Blood Epidemiology and Clinical Therapeutics Branch, Division of Blood Diseases and Resources, National Heart, Lung, and Blood Institute, Bethesda, Maryland, USA.

${ }^{3}$ Clinical Applications and Prevention Branch, Division of Cardiovascular Sciences, National Heart, Lung, and Blood Institute, Bethesda, Maryland, USA.

*These co-authors contributed equally and are listed in alphabetical order.

() Juanita J. Chinn et al. 2021; Published by Mary Ann Liebert, Inc. This Open Access article is distributed under the terms of the Creative Commons Attribution Noncommercial License (http://creativecommons.org/licenses/by-nc/4.0/) which permits any noncommercial use, distribution, and reproduction in any medium, provided the original author(s) and the source are cited.
}

Correction added on February 19, 2021 after first online publication of November 25, 2020: The article reflects Open Access, with copyright transferring to the author(s), and a Creative Commons Attribution Noncommercial License (CC-BY-NC) added (http:// creativecommons.org/licenses/by-nc/4.0/). 
Table 1. Descriptive Demographic Statistics FOR Black Women In the United States, 2018

\begin{tabular}{|c|c|c|}
\hline & $\begin{array}{c}\text { Black } \\
\text { women }\end{array}$ & $\begin{array}{c}\text { All } \\
\text { women }\end{array}$ \\
\hline Percentage of population & 7.0 & 51.5 \\
\hline Percentage of women & 13.6 & 100.0 \\
\hline Mean age (years) & 36.1 & 39.6 \\
\hline Percentage currently married & 26.0 & 46.0 \\
\hline \multicolumn{3}{|l|}{ Percentage educational attainment } \\
\hline Less than high school & 13 & 11 \\
\hline High school & 29 & 26 \\
\hline Greater than high school & 58 & 63 \\
\hline Percentage poverty & 24 & 14 \\
\hline Percentage owner-occupied housing ${ }^{\mathrm{a}}$ & 41.4 & 63.9 \\
\hline Percentage head of household & 27 & 12 \\
\hline
\end{tabular}

Data are collected by sex (female).

Data source: https://blackdemographics.com/population/blackwomen-statistics ${ }^{10}$

${ }^{\mathrm{a}}$ Data are from 2017 and are for both sexes.

Research consistently has documented the continued impacts of systematic oppression, bias, and unequal treatment of Black women, ${ }^{5,8,9}$ Substantial evidence exists that racial differences in socioeconomic (e.g., education and employment) and housing outcomes among women are the result of segregation, discrimination, and historical laws purposed to oppress Blacks and women in the United States.

Black women earn on average $\$ 5,500$ less per year and experience higher unemployment and poverty rates than the U.S. average for women (Table 1) ${ }^{10}$ Moreover, Black women are more likely to be the head of household than their White counterparts, effectively supporting more dependents with fewer resources. ${ }^{10}$ Black women live in neighborhoods that are more racially segregated and have lower property values than their White counterparts. ${ }^{10,11}$ Mortgage lending discrimination ("redlining"), a legal practice in which lenders deny mortgage loans to communities and individuals based on race, resulted in community disinvestment residential segregation. ${ }^{11}$ Residential segregation, as Williams and Collins argued, ${ }^{12}$ is a fundamental cause of racial disparities in health, operating through many social institutions (including labor markets and education) to affect health.

The intersectionality of gender and race and its impact on the health of Black women also is important. This intersection of race and gender for Black women is more than the sum of being Black or being a woman: It is the synergy of the two. Black women are subjected to high levels of racism, sexism, and discrimination at levels not experienced by Black men or White women. ${ }^{13-15}$

In contrast to Black women, White women in the United States have benefited from living in a politically, culturally, and socioeconomically White-dominated society. ${ }^{1}$ These benefits accumulate across generations, creating a cycle of overt and covert privileges ${ }^{16,17}$ not afforded to Black women, such as wage gap differentials ${ }^{18}$ and the invisibility of whiteness (i.e., not having to think about one's race). ${ }^{19,20}$ These privileges do not mean that all White women are similarly advantaged nor are all Black women similarly disadvantaged.

These social conditions create the environment for health disparities to exist and persist. They are the social determinants of health, the "conditions in the environments in which people are born, live, learn, work, play, worship, and age that affect a wide range of health, functioning, and quality-oflife outcomes and risks." 21 Disparities in Black women's health are particular types of health differences "that are closely linked with social, economic, and/or environmental disadvantage." 21

The history of Black women's access to health care and treatment by the U.S. medical establishment, particularly in gynecology, contributes to the present-day health disadvantages of Black women. Health inequality among Black women is rooted in slavery. White slave holders viewed enslaved Black women as a means of economic gain, resulting in the abuse of Black women's bodies and a disregard for their reproductive health. Black women were forced to procreate, with little or no self-agency and limited access to medical care. ${ }^{22}$ The development of gynecology as a medical specialty in the $1850 \mathrm{~s}^{23}$ ushered in a particularly dark period for the health of Black women. With no regulations for the protection of human subjects in research, Black women were subjected to unethical experimentation without consent. ${ }^{22-24}$ Even in more contemporary times, these abuses continue. ${ }^{25,26}$

As a result of this history and the accumulation of disadvantages across generations, Black women are at the center of a public health emergency. Maternal mortality rates for non-Hispanic Black women are three to four times the maternal mortality rates of non-Hispanic White women. ${ }^{2}$ In the next section of this article, we highlight some of the physical and mental health disparities that contribute to the current maternal mortality rates. Although discussed separately, physical health and mental health are inextricably linked.

\section{Physical Health}

\section{Demographic characteristics}

Black women are diverse in both nativity and ethnicity. ${ }^{27}$ They are not a monolithic group; instead, they comprise multiple cultures and languages. For the purposes of this article, "Black women" refers to the collective identities of Black women, including women of different ethnicities. In the data cited here, "Black women" refers to the women included in the original study population.

Black women currently make up $\sim 7.0 \%$ of the U.S. population and $13.6 \%$ of all U.S. women. ${ }^{10}$ Although, on average, Black women are younger (36.1 years) than U.S. women overall (39.6 years) (Table 1), ${ }^{10}$ they have a higher prevalence of many health conditions, including heart disease, stroke, cancers, diabetes, maternal morbidities, obesity, and stress. Life expectancy at birth is 3 years longer for non-Hispanic White females than for non-Hispanic Black females. Infant mortality rates for children born to non-Hispanic Black women are twice as high as those for children born to non-Hispanic White women ${ }^{1}$ (Table 2).

\section{Weathering}

As adults age, their health declines. Aging is affected not only by chronological age but also by biological, behavioral, sociocultural, and environmental factors. ${ }^{31}$ Stress, an important factor in aging, is affected strongly by exposure to the built and social environments. Geronimus et al. posit the weathering hypothesis, that is differential exposures to stressful environments are a major factor in widening health disparities as individuals age. They suggest that Black-White 
Table 2. Descriptive Health Statistics for Women

\begin{tabular}{|c|c|c|c|}
\hline & $\begin{array}{l}\text { Non- } \\
\text { Hispanic } \\
\text { Black } \\
\text { women }\end{array}$ & $\begin{array}{l}\text { Non- } \\
\text { Hispanic } \\
\text { White } \\
\text { women }\end{array}$ & $\begin{array}{c}\text { All } \\
\text { women }\end{array}$ \\
\hline $\begin{array}{l}\text { Life expectancy at birth } \\
\quad(\text { years })^{\mathrm{a}}\end{array}$ & 77.9 & 81.0 & 81.0 \\
\hline Infant mortality ${ }^{\mathrm{a}}$ & 10.9 & 4.7 & 5.8 \\
\hline Maternal mortality $^{\mathrm{b}}$ & 37.1 & 14.7 & 17.4 \\
\hline $\begin{array}{l}\text { Pregnancy-related } \\
\text { mortality }\end{array}$ & 42.4 & 13.0 & 16.9 \\
\hline \multicolumn{4}{|c|}{ Physical health (prevalence \%) } \\
\hline Heart disease $\mathrm{d}^{\mathrm{T}}$ & 9.9 & 10.8 & 10.1 \\
\hline Hypertension $^{\mathrm{e}}$ & 39.9 & 25.6 & 27.7 \\
\hline Obesity $^{\mathrm{b}}$ & 34.7 & 21.6 & 23.5 \\
\hline \multicolumn{4}{|c|}{ Mental health (prevalence \%) } \\
\hline $\begin{array}{l}\text { Serious psychological } \\
\text { distress }^{\mathrm{a}}\end{array}$ & 4.7 & 4.8 & 4.8 \\
\hline $\begin{array}{l}\text { Suicide (per } 100,000 \\
\text { population) }\end{array}$ & 2.8 & 7.9 & 6.1 \\
\hline
\end{tabular}

Maternal mortality and pregnancy-related mortality are per 100,000 live births.

Infant mortality rates are per 1,000 live births.

Data sources:

${ }^{a}$ Health, United States, 2017. ${ }^{28}$

${ }^{b}$ National Center for Health Statistics, 2020. ${ }^{29}$

${ }^{\mathrm{C}}$ Centers for Disease Control and Prevention, 2020. ${ }^{2}$

${ }^{\mathrm{d}}$ Health, United States, 2018.

${ }^{\mathrm{e}}$ National Center for Health Statistics, 2017. ${ }^{30}$

disparities in health widen with age because of the accumulation of socioeconomic disadvantages and experiences with racism among Black women throughout the life course. ${ }^{31-35}$ Evidence for the weathering hypothesis includes the finding that babies born to Black women in their teens are at lower risk of infant mortality than babies born to older nonHispanic Black women, the reverse of what is observed for non-Hispanic White women. ${ }^{31}$ More recently, Geronimus et al. found that among women aged 49-55 years, telomere length (a biomarker of aging) indicates that Black women are 7.5 years biologically "older" than White women. Perceived stress and poverty account for $27 \%$ of this difference. ${ }^{33}$

\section{Obesity}

The relatively high levels of morbidity and mortality among Black populations in the United States are, in large part, caused by obesity, which increases the risk of stroke and various CVDs. ${ }^{36-38}$ Obesity is a major source of morbidity and mortality for all U.S. populations, but non-Hispanic Blacks have a higher age-adjusted prevalence of obesity than any other racial/ethnic group, with estimates ranging from $34 \%$ to $50 \% .^{39}$ Patterns of obesity vary by many factors across and within races, including location, gender, and educational attainment. ${ }^{40}$ Unlike other demographic groups, higher levels of income are not protective against obesity among non-Hispanic Black women. ${ }^{39}$ This difference in the prevalence of obesity as reflected in national adiposity data on Black women is the result of the complex multilevel interplay of the measurable and difficult-to-measure social determinants that affect health disparities. Furthermore, Black women lose less weight than other subpopulations do in behavioral weight loss intervention research, ${ }^{41}$ and they have a positive body self-image at higher weight levels, which may be psychologically healthy, but also diminishes their motivation to lose weight. ${ }^{42}$ These findings support the need for interventions that integrate biological, sociocultural, and environmental factors that influence obesity. ${ }^{41}$ The high prevalence of obesity among Black women ${ }^{36,37}$ impacts the prevalence rates of stroke and various CVDs. ${ }^{38}$

\section{Cardiovascular disease}

After 50 years of declines in CVD mortality, declines stalled in 2011, with CVD mortality increasing starting in $2015 .{ }^{43-45}$ Despite changes in the overall CVD mortality rates, racial and sex disparities persist. Compared with White women, Black women have higher rates of CVD mortality, which have been attributed to poorer cardiovascular (CV) health and a higher burden of modifiable risk factors and clinical comorbidities. ${ }^{46,47}$ Furthermore, the accumulation of both clinical and behavioral $\mathrm{CV}$ risk factors and the manifestation of CVD at younger ages for Black women compared with other racial and ethnic groups - that is, during young adulthood and middle adulthood-have significant implications for maternal and infant health. ${ }^{48}$ Understanding the drivers of disparities in CVD among Black women requires examining the intersection of sex as a biological variable ${ }^{49}$ and multi-omic influences (e.g., genetic ancestry ${ }^{50}$ and epigenetic characterization) with multilevel $^{51}$ (e.g., biological ancestry characterization, individual, interpersonal, community, and society) social constructs (e.g., race, ethnicity, and gender).

Although differences in CVD incidence, prevalence, morbidity, and mortality by sex and race/ethnicity are well documented, research on the contributions of genetic factors is limited. People of African ancestry have been underrepresented in genomic research ${ }^{52}$ Furthermore, in genomic studies, analyses of sex chromosomes and the interaction between sex hormones and genetic characteristics are rarely included. ${ }^{53}$ Therefore, significant concerns exist about the potential for precision medicine efforts, such as polygenic risk scores, to exacerbate CVD health disparities when using precision medicine research that relies on genetic studies that had inadequate participation from populations with African ancestry. ${ }^{54}$

Optimizing such behavioral factors as diet, physical activity, sleep, smoking, alcohol use, emotional health, and stress management is important to maintaining CV health (primordial prevention) and reducing CVD risk (primary and secondary prevention). ${ }^{55-59}$ Compared with non-Hispanic White women, non-Hispanic Black women aged 20 years and older have a higher prevalence of several clinical risk factors for CVD, including obesity, high blood pressure, and diabetes. ${ }^{60}$

Sleep disparities may contribute to racial/ethnic disparities in CVD. ${ }^{61,62}$ Blacks have a higher likelihood of short or prolonged sleep durations, obstructive sleep apnea, insomnia, and other measures of poor sleep quality. A study of women of childbearing age showed that, despite Black women having poorer self-reported sleep quality, they were less likely than other women to report their sleep disturbances to a physician. ${ }^{63}$ Sleep disturbances may be a manifestation of altered stress reactivity resulting in activation of the chronic stress response and resultant elevations in cardiometabolic disease. ${ }^{64}$

\section{Bleeding and blood disorders}

Diseases of the blood are as numerous and complex as the fields of hematological physiology and pathophysiology. 
Benign blood disease include anemia (iron deficiencies), sickle cell anemia (SCD), glucose-6-phosphate dehydrogenase disorders, and hemophilia, among others. Malignant blood diseases (cancers of the blood) include acute myeloid leukemia, acute lymphocytic leukemia, multiple myeloma, non-Hodgkin lymphoma, Hodgkin lymphoma, myeloproliferative neoplasms, and myelodysplastic syndrome. Well-documented differences exist in the prevalence, treatment experiences, and outcomes across races and ethnicities for most benign blood diseases, ${ }^{65,66}$ and interest in observed disparities in malignancies of the blood is emerging. ${ }^{67,68}$ Black women are disproportionately impacted by SCD and its complications, as well as by anemia (almost all forms), and they have poor outcomes associated with ancestrally linked disorders, such as G6PD. ${ }^{69,70}$

\section{Maternal morbidity and mortality}

It is estimated that non-Hispanic Black women are three to almost four times more likely to die while pregnant or within 1 year postpartum than their non-Hispanic White and Latina counterparts. ${ }^{2}$ The racial disparity in mortality persists at every education level ${ }^{2}$ and has persisted or increased over time. ${ }^{71}$ As detailed in the sections above, Black women have elevated prevalence rates of chronic conditions associated with higher risk of severe maternal morbidity and mortality. ${ }^{72}$ Some of the leading causes of maternal morbidities resulting in pregnancy-associated death occur more in non-Hispanic Black women (e.g., hemorrhage, infection [sepsis], thrombotic pulmonary/other embolism, and pregnancy-associated hypertensive disorders). ${ }^{72}$ However, changes in the prevalence of these risk factors do not fully account for the increasing trends in severe maternal morbidity ${ }^{73}$ and subsequent mortality among non-Hispanic Black women over time. ${ }^{73}$

Examination of nonclinical factors, such as hospital quality $^{74,75}$ (the degree to which health services for individuals and populations increase the likelihood of desired health outcomes) and access to quality care, helps to explain some of the disparities in maternal mortality. Howell et al. ${ }^{74,75}$ found that women from racial and ethnic minority groups give birth in lower quality hospitals and in hospitals with higher rates of severe maternal morbidity. Using a simulation model, they found that if non-Hispanic Black women gave birth at the same hospitals as non-Hispanic White women, the non-Hispanic Black severe maternal morbidity rate would decrease by $47.7 \%$, from $4.2 \%$ to $2.9 \%$ (1.3 events per 100 deliveries per year). ${ }^{74,76-79}$ Qualitative research reveals that many non-Hispanic Black women giving birth in lowperforming hospitals experience poor patient-provider communication and difficulties in obtaining appropriate prenatal and postpartum care. ${ }^{74,75}$

Additionally, homicide is a leading cause of death during pregnancy and postpartum, yet it remains understudied. Typically, homicide is not captured in examinations of pregnancy-related deaths or maternal mortality. Wallace et al. ${ }^{80}$ argue that failure to identify and address factors underlying pregnancy-associated homicide will perpetuate racial inequity in mortality during pregnancy and the postpartum period.

\section{Mental Health}

National epidemiological surveillance systems that capture information on health risk behaviors and mental health care access_-including suicide attempts/occurrence, depression, anxiety, and clinical encounters that record concerns associated with mental health and substance abuse-have notable limitations. Measurement of race and gender across mental health studies varies considerably, creating a dearth of longitudinal research on the nuances of the mental health status of Black women. Even if the experiences of Black women as a racial-gender subgroup are captured with sufficient statistical power to report stratified results of survey findings (Table 2), the results must be interpreted through the lens of the full scope of Black women's experiences in the United States.

Racial discrimination is a toxic "uncontrollable or unpredictable" stressor that is associated not only with poor physical health but also with psychological stress. ${ }^{76-78,81-85}$ Chronic stressors reduce coping resources and increase vulnerability to mental health problems. ${ }^{76,85}$ Non-Hispanic Blacks with higher levels of multiple stress measures are less likely to achieve intermediate or ideal levels of overall CV health. ${ }^{86}$ Research suggests that chronic exposure to environmental stressors, such as racism, across the life span contributes to the weathering of the health of Black women, increasing their allostatic load and, consequently, compromising their reproductive health. ${ }^{76,77,81-85}$ Allostatic load is a measure of the physiological dysregulation that results from cumulative chronic stress on the body. ${ }^{76,87}$ It is a relevant measure for health disparities research because it can be utilized to assess racial/ethnic differences in biological responses to stressors and their relationship with adverse health outcomes. $^{83}$

\section{Maternal mental health}

Perceived stress from chronic experiences of discrimination has been found to be a significant predictor of poor birth outcomes. ${ }^{76}$ Indeed, non-Hispanic Black women are twice as likely to have a low-birth weight infant than non-Hispanic White women. ${ }^{76}$ Non-Hispanic Black women are at a disadvantage regarding the protective factor of the early initiation of prenatal care, with $67 \%$ participating in prenatal care in the first trimester compared with $77 \%$ of non-Hispanic White women and $81 \%$ of Asian women. ${ }^{76}$ This is problematic, given that the delivery of perinatal mental health services is critical, particularly for non-Hispanic Black and Latina women because they experience higher rates of depression and anxiety during pregnancy and are at greater risk of poor pregnancy outcomes. $^{76,77,81-84,88,89}$ Perinatal depression has been linked to risks for adverse maternal and birth outcomes, including preeclampsia, gestational diabetes, preterm birth, and low birth weight. ${ }^{76,90-92}$ Specifically, it is estimated that up to $28 \%$ of non-Hispanic Black women experience perinatal depression. ${ }^{89}$

\section{Conclusions}

The health of Black women is measured in their disproportionally poor health outcomes, but it is a result of a complex milieu of barriers to quality health care, racism, and stress associated with the distinct social experiences of Black womanhood in U.S. society. Black women are characterized by incredible resilience in the face of adversity and continue to experience improvements in health, even with the socioeconomic contexts that allow disparities to persist. Despite recent mandates by the National Institutes of Health $(\mathrm{NIH})$ to enhance the inclusion of women and racial/ethnic groups that are underrepresented in biomedical research in all NIHfunded research projects, ${ }^{66}$ Black women continue to be 
underrepresented, ${ }^{93-96}$ and the resulting interventions may not reflect the unique needs of Black women. Moreover, there is a dearth of current and accessible data on Black women that examines the diversity of Black women (nativity, ethnicity, and country of ancestry). Demographic and health data at the intersection of race and gender are critical to understanding the trends and opportunities for intervention and prevention.

Racism and gender discrimination have profound impacts on the well-being of Black women. Evidence-based care models that are informed by equity and reproductive justice frameworks (reproductive rights as human rights) ${ }^{76,84}$ need to be explored to address disparities throughout the life course, including the continuum of maternity care, and to ensure favorable outcomes for all women. ${ }^{79}$ Interventions to enhance patient-health care provider interactions include raising awareness about the implicit biases that a provider may hold. ${ }^{97}$ Black women have continued to make significant inroads in many disciplines yet remain one of few demographic groups that must advocate for themselves to receive consistent and high-quality care. We have outlined disparities in several health conditions and the dire mortality outcomes experienced by Black women. Health does not exist outside its social context. Without equity in social and economic conditions, health equity is unlikely to be achieved, ${ }^{98}$ and one cost of health inequality has been the lives of Black women.

\section{Disclaimer}

The views expressed in this article are those of the authors and do not necessarily represent the views of the Eunice Kennedy Shriver National Institute of Child Health and Human Development; the National Heart, Lung, and Blood Institute; the National Institutes of Health; or the U.S. Department of Health and Human Services.

\section{Acknowledgment}

The authors extend their enormous gratitude to Dr. Beda Jean-Francois for her tireless work and feedback on this article.

\section{Author Disclosure Statement}

No competing financial interests exist.

\section{Funding Information}

No funding was received for this article.

\section{References}

1. National Center for Health Statistics. Health, United States, 2018. 2019. Available at: https://www.cdc.gov/nchs/data/ hus/hus18.pdf Accessed May 16, 2020.

2. Centers for Disease Control and Prevention. Infographic: Racial/ethnic disparities in pregnancy-related deathsUnited States, 2007-2016. 2020. Available at: https://www .cdc.gov/reproductivehealth/maternal-mortality/disparitiespregnancy-related-deaths/infographic.html Accessed May $16,2020$.

3. Saenz R, Morales MC. Demography of race and ethnicity. In: Poston DL, Micklin M, eds. Handbook of population. New York, NY: Kluwer Academic/Plenum Publishers, 2005: 169-206.
4. Waters M. The social construction of race and ethnicity: Some examples from demography. In: Denton NA, Tolnay SE, eds. American diversity: A demographic challenge for the twenty-first century. Albany, NY: State University of New York Press, 2002:25-49.

5. Williams DR, Sternthal M. Understanding racial-ethnic disparities in health: Sociological contributions. J Health Soc Behav 2010;51(Suppl):S15-S27.

6. Office of Budget and Management. Standards for maintaining, collecting, and presenting federal data on race and ethnicity. Fed Regist 2016;81:67398-67401.

7. Hummer RA, Chinn JJ. Race/ethnicity and U.S. adult mortality: Progress, prospects, and new analyses. Du Bois Rev 2011;8:5-24.

8. Anderson E, Massey DS, eds. Problem of the century: Racial stratification in the United States. New York, NY: Russell Sage Foundation, 2001.

9. Oliver ML, Shapiro TM. Black wealth/White wealth, 2nd ed. New York, NY: Routledge, 2006.

10. Black Demographics. Black women: Statistics. Available at: https://blackdemographics.com/population/black-womenstatistics/ Accessed May 17, 2020.

11. Massey DS, Denton NA. American apartheid: Segregation and the making of the underclass. Cambridge, MA: Harvard University Press, 1993.

12. Williams DR, Collins C. Racial residential segregation: A fundamental cause of racial disparities in health. Public Health Rep 2001;116:404-416.

13. Roberts DE. Killing the Black Body: Race, Reproduction, and the meaning of liberty. New York, NY: Pantheon Books, 1997.

14. Hooks B. Ain't I a Woman: Black women and feminism. Boston, MA: South End Press, 1981.

15. Crenshaw K. The urgency of intersectionality. TED October 2016. Available at: https://www.ted.com/talks/ kimberle_crenshaw_the_urgency_of_intersectionality? language=en Accessed May 16, 2020.

16. Bonilla-Silva E. Racism Without Racists: Color blind racism and the persistence of racial inequality in the United States. Lanham, MD: Rowman and Littlefield Publishers, 2003.

17. Feagin JR. Racist America: Roots, current realities, and future reparations. New York, NY: Routledge, 2001.

18. American Association of University Women. Miller K, Vagins DJ. the simple truth about the gender pay gap. Fall 2018. Available at: https://eric.ed.gov/?id=ED596219 Accessed July 27, 2020.

19. Hudson D, Sacks T, Irani K, Asher A. The price of the ticket: Health costs of upward mobility among African Americans. Int J Environ Res Public Health 2020;17:1179.

20. Frankenberg, R. White women, race matters: The social construction of whiteness. Minneapolis, MN: University of Minnesota Press, 1993.

21. Office of Disease Prevention and Health Promotion, U.S. Department of Health and Human Services. Healthy people 2020. Available at: https://www.healthypeople.gov/ Accessed May 16, 2020.

22. Amutah-Onukagha N. Maternal health equity Webinar Series: Part 1 context and past. Lecture presented at the AAMC Maternal Health Equity Webinar Series, April 15, 2020. Available at: https://www.aamc.org/what-we-do/missionareas/medical-research/health-equity/training-opportunities Accessed November 13, 2020.

23. Hardeman, RR. Disparities and social determinants of maternal mortality. NICHD Maternal Mortality Workshop. 
Lecture presented at Maternal Mortality in the United States: Future Research Directions Workshop, Rockville, MD, May 3, 2019.

24. Washington HA. Medical apartheid: The dark history of medical experimentation on Black Americans from colonial times to the present. New York, NY: Doubleday Books, 2007.

25. Johns Hopkins Medicine. The Legacy of Henrietta Lacks. Available at: https://www.hopkinsmedicine.org/henrietta lacks/ Accessed May 22, 2020.

26. Silliman J, Gerber M, Ross L, Gutiérrez E. Undivided rights: Women of color organizing for reproductive justice. Chicago, IL: Haymarket Books, 2016.

27. Agyemang C, Bhopal R, Bruijnzeels M. Negro, Black, Black African, African Caribbean, African American or what? Labelling African origin populations in the health arena in the 21 st century. $\mathbf{J}$ Epidemiol Community Health 2005;59:1014-1018.

28. National Center for Health Statistics. Health, United States, 2017. Hyattsville, MD: National Center for Health Statistics, 2018.

29. Hoyert DL, Miniño AM. Maternal mortality in the United States: Changes in coding, publication, and data release, 2018. National Vital Statistics Reports 69(2). Hyattsville, MD: National Center for Health Statistics, 2020.

30. Fryar CD, Ostchega Y, Hales CM, Zhang G, KruszonMoran D. Hypertension prevalence and control among adults: United States, 2015-2016. NCHS Data Brief No 289. Hyattsville, MD: National Center for Health Statistics, 2017.

31. Geronimus AT. The weathering hypothesis and the health of African American women and infants. Ethn Dis 1992;2: 207-221.

32. Geronimus AT, Bound J, Waidmann TA, Hillemeier MM, Burns PB. Excess mortality among Blacks and Whites in the United States. N Engl J Med 1996;335:1552-1558.

33. Geronimus AT, Hicken MT, Pearson JA, Seashots SJ, Brown KL, Cruz TD. Do U.S. Black women experience stress-related accelerated biological aging? A novel theory and first population-based test of black-white differences in telomere length. Hum Nat 2010;21:19-38.

34. Simons RL, Lei MK, Beach SR, et al. Economic hardship and biological weathering: The epigenetics of aging in a U.S. sample of Black women. Soc Sci Med 2016;150:192200.

35. Thorpe RJ Jr, Fesahazion RG, Parker L, et al. Accelerated health declines among African Americans in the USA. J Urban Health 2016;93:808-819.

36. Caspard H, Jabbour S, Hammar N, Fenici P, Sheehan JJ, Kosiborod M. Recent trends in the prevalence of type 2 diabetes and the association with abdominal obesity lead to growing health disparities in the USA: An analysis of the NHANES surveys from 1999 to 2014. Diabetes Obes Metab 2018;20:667-671.

37. Massetti GM, Dietz WH, Richardson LC. Excessive weight gain, obesity, and cancer: Opportunities for clinical intervention. JAMA 2018;318:1975-1976.

38. Bauza C, Martin R, Yeatts SD, et al. Determining the joint effect of obesity and diabetes on all-cause mortality and cardiovascular-related mortality following an ischemic stroke. Stroke Res Treat 2018;2018:4812712.

39. Ogden CL, Fakhouri TH, Carroll MD, et al. Prevalence of obesity among adults, by household income and educa-
tion-United States, 2011-2014. MMWR Morb Mortal Wkly Rep 2017;66:1369-1373.

40. Hales CM, Carroll MD, Fryar CD, Ogden CL. Prevalence of obesity and severe obesity among adults: United States, 2017-2018. NCHS Data Brief No. 360. Hyattsville, MD: National Center for Health Statistics, 2020.

41. Fitzgibbon ML, Tussing-Humphreys LM, Porter JS, Martin IK, Odoms-Young A, Sharp LK. Weight loss and AfricanAmerican women: A systematic review of the behavioral weight loss intervention literature. Obes Rev 2012;13:193213.

42. Chithambo TP, Huey SJ. Black/White differences in perceived weight and attractiveness among overweight women. J Obes 2013;2013:320326.

43. Sidney S, Quesenberry CP Jr, Jaffe MG, et al. Recent trends in cardiovascular mortality in the United States and public health goals. JAMA Cardiol 2016;1:594-599.

44. Sidney S. Wrong direction: Troubling trends in the rate of U.S. cardiovascular disease deaths: A report from the National Forum for Heart Disease \& Stroke Prevention. 2017. Available at: https://www.nationalforum.org/wpcontent/uploads/2017/11/NF_WrongDirection_WP_110717_ Web.pdf Accessed June 19, 2020.

45. Bairey Merz CN. Three decades of progress in cardiovascular disease in women: Where are we? J Womens Health 2019;28:673-674.

46. Benjamin EJ, Muntner P, Alonso A, et al. Heart disease and stroke statistics-2019 Update: A report from the American Heart Association. Circulation 2019;139:e56-e528.

47. Kalinowski J, Taylor JY, Spruill TM. Why are young Black women at high risk for cardiovascular disease? Circulation 2019;139:1003-1004.

48. Pool LR, Ning H, Lloyd-Jones DM, Allen NB. Trends in racial/ethnic disparities in cardiovascular health among U.S. adults from 1999-2012. J Am Heart Assoc 2017;6: e006027.

49. Institute of Medicine Committee on Understanding the Biology of Sex and Gender Differences. Wizemann TM, Pardue ML, eds. Exploring the biological contributions to human health: Does sex matter? Washington, DC: National Academies Press, 2001.

50. Kittles RA, Weiss KM. Race, ancestry, and genes: Implications for defining disease risk. Annu Rev Genomics Hum Genet 2003;4:33-67.

51. National Institute of Minority Health and Health Disparities. NIMHD Research Framework. 2018. Available at: https://www.nimhd.nih.gov/about/overview/research-frame work/nimhd-framework.html Accessed June 19, 2020.

52. Sirugo G, Williams SM, Tishkoff SA. The missing diversity in human genetic studies. Cell 2019;177:26-31.

53. Winham SJ, de Andrade M, Miller VM. Genetics of cardiovascular disease: Importance of sex and ethnicity. Atherosclerosis 2015;241:219-228.

54. Martin AR, Kanai M, Kamatani Y, Okada Y, Neale BM, Daly MJ. Clinical use of current polygenic risk scores may exacerbate health disparities. Nat Genet 2019;51: 584-591.

55. Yu E, Malik VS, Hu FB. Cardiovascular disease prevention by diet modification. J Am Coll Cardiol 2018;72:914926.

56. Kalkhoran S, Benowitz NL, Rigotti NA. Prevention and treatment of tobacco use. J Am Coll Cardiol 2018;72:1030 1045. 
57. Kubzansky LD, Huffman JC, Boehm JK, et al. Positive psychological well-being and cardiovascular disease. J Am Coll Cardiol 2018;72:1382-1396.

58. Fletcher GF, Landolfo C, Niebauer J, Ozemek C, Arena R, Lavie CJ. Promoting physical activity and exercise. J Am Coll Cardiol 2018;72:1622-1639.

59. Buxton OM, Marcelli E. Short and long sleep are positively associated with obesity, diabetes, hypertension, and cardiovascular disease among adults in the United States. Soc Sci Med 2010;71:1027-1036.

60. Virani SS, Alonso A, Benjamin EJ, et al. Heart disease and stroke statistics-2020 update: A report from the American Heart Association. Circulation 2020;141:e139-e596.

61. Jackson CL, Redline S, Emmons KM. Sleep as a potential fundamental contributor to disparities in cardiovascular health. Annu Rev Public Health 2015;36:417440.

62. Jackson CL, Powell-Wiley TM, Gaston SA, Andrews MR, Tamura K, Ramos A. Racial/ethnic disparities in sleep health and potential interventions among women in the United States. J Womens Health 2020;29:435-442.

63. Amyx M, Xiong X, Xie Y, Buekens P. Racial/ethnic differences in sleep disorders and reporting of trouble sleeping among women of childbearing age in the United States. Matern Child Health J 2017;21:306-314.

64. Goosby BJ, Straley E, Cheadle JE. Discrimination, sleep, and stress reactivity: Pathways to African American-White cardiometabolic risk inequities. Popul Res Policy Rev 2017;36:699-716.

65. McLaughlin JM, Lambing A, Witkop ML, Anderson TL, Munn J, Tortella B. Racial differences in chronic pain and quality of life among adolescents and young adults with moderate or severe hemophilia. J Racial Ethn Health Disparities 2016;3:11-20.

66. Kochanek KD, Murphy SL, Xu J, Arias E. Deaths: Final data for 2017. Natl Vital Stat Rep 2019;68:1-77.

67. Smith CJ, Ambs S, Landgren O. Biological determinants of health disparities in multiple myeloma. Blood Cancer $\mathrm{J}$ 2018;8:85.

68. Kirtane K, Lee SJ. Racial and ethnic disparities in hematologic malignancies. Blood 2017;130:1699-1705.

69. Francis RO, Jhang JS, Pham HP, Hod EA, Zimring JC, Spitalnik SL. Glucose-6-phosphate dehydrogenase deficiency in transfusion medicine: The unknown risks. Vox Sang 2013;105:271-282.

70. Howard J, Telfer P. Sickle cell disease in clinical practice. London: Springer-Verlag, 2015.

71. Petersen EE, Davis NL, Goodman D, et al. Racial/ethnic disparities in pregnancy-related deaths-United States, 2007-2016. MMWR Morb Mortal Wkly Rep 2019;68:762765.

72. Centers for Disease Control and Prevention. Pregnancy mortality surveillance system. 2020. Available at: https:// www.cdc.gov/reproductivehealth/maternal-mortality/preg nancy-mortality-surveillance-system.htm Accessed May 2020.

73. Leonard SA, Main EK, Scott KA, Profit J, Carmichael SL. Racial and ethnic disparities in severe maternal morbidity prevalence and trends. Ann Epidemiol 2019;33:30-36.

74. Howell EA, Zeitlin J. Improving hospital quality to reduce disparities in severe maternal morbidity and mortality. Semin Perinatol 2017;41:266-272.

75. Howell EA, Egorova NN, Janevic R, et al. Race and ethnicity, medical insurance, and within-hospital severe maternal morbidity disparities. Obstet Gynecol 2020;135: 285-293.

76. National Academies of Sciences, Engineering, and Medicine. Birth settings in America: Improving outcomes, quality, access, and choice. Washington, DC: The National Academies Press, 2020. Available at: https://www.nap.edu/ catalog/25636/birth-settings-in-america-outcomes-qualityaccess-and-choice Accessed November 13, 2020.

77. Prather C, Fuller TR, Jeffires WL, et al. Racism, African American men, and their sexual and reproductive health: A review of historical and contemporary evidence and implications for health equity. Health Equity 2018;291: 249-259.

78. Howell EA, Egorova NN, Balbierz A, Zeitlin J, Hebert PL. Site of delivery contribution to black-white severe maternal morbidity disparity. Obstet Gynecol 2016;215:143-152.

79. Howell EA, Ahmed ZN. Eight steps for narrowing the maternal health disparity gap: Step-by-step plan to reduce racial and ethnic disparities in care. Contemp Ob Gyn 2019;64:30-36.

80. Wallace ME, Crear-Perry J, Mehta PK, Theall KP. Homicide during pregnancy and the postpartum period in Louisiana, 2016-2017. JAMA Pediatr 2020;174:387-388.

81. Ohm JE. Environmental exposures, the epigenome, and African American women's health. J Urban Health 2019; 96(Suppl 1):S50-S56.

82. Scott KA, Britton L, McLemore MR. The ethics of perinatal care for Black women: Dismantling the structural racism in "Mother Blame" narratives. J Perinat Neonat Nurs 2019;33:108-115.

83. Rodriguez EJ, Kim EN, Summer AE, Napoles AM, PerezStable EJ. Allostatic load: Importance, markers, and score determination in minority and disparity populations. J Urban Health 2019;96(Suppl 1):S3-S11.

84. Muse S, Gay ED, Aina AD, et al. Setting the standard for holistic care of and for Black Women. Black Paper. Atlanta, GA: Black Mamas Matter Alliance, April 2018. Available at: http://blackmamasmatter.org/wp-content/ uploads/2018/04/BMMA_BlackPaper_April-2018.pdf Accessed November 13, 2020.

85. Barajas CB, Jones SCT, Milam AJ, et al. Coping, discrimination, and physical health conditions among predominantly poor, urban African Americans: Implications for community-level health services. J Community Health 2019;44:954-962.

86. Brewer LC, Redmond N, Slusser JP, et al. Stress and achievement of cardiovascular health metrics: The American Heart Association Life's Simple 7 in Blacks of the Jackson Heart Study. J Am Heart Assoc 2018;7: e008855.

87. McEwen BS, Gianaros PJ. Central role of the brain in stress and adaptation: Links to socioeconomic status, health, and disease. Ann NY Acad Sci 2010;1186:190-222.

88. Gennaro S, O'Connor C, Anne M, et al. Perinatal anxiety and depression in minority women. MCN Am J Matern Child Nurs 2020;45:138-144.

89. Lara-Cinisomo S, Clark CT, Wood J. Increasing diagnosis and treatment of perinatal depression in Latinas and African American women: Addressing stigma is not enough. Womens Health Issues 2018;28:201-204.

90. Admon LK, Windelman TN, Moniz MH, Davis MM, Heisler M, Dalton VK. Disparities in chronic conditions among women hospitalized for delivery in the United States, 2005-2014. Obstet Gynecol 2017;130:1319-1326. 
91. Kozhimannil KB, Pereira MA, Harlow BL. Association between diabetes and perinatal depression among lowincome mothers. JAMA 2009;301:842-847.

92. Kurki T, Hiilesmaa V, Raitasalo R, Mattila H, Ylikorkala $\mathrm{O}$. Depression and anxiety in early pregnancy and risk for preeclampsia. Obstet Gynecol 2000;95:487-490.

93. National Institutes of Health Revitalization Act of 1993. Public Law 103-43.

94. Zhang T, Tsang W, Wijeysundera HC, Ko DT. Reporting and representation of ethnic minorities in cardiovascular trials: A systematic review. Am Heart J 2013;166:52-57.

95. Melloni C, Berger JS, Wang TY, et al. Representation of women in randomized clinical trials of cardiovascular disease prevention. Circ Cardiovasc Qual Outcomes 2010;3: 135-142.

96. Flaskerud JH, Nyamathi AM. Attaining gender and ethnic diversity in health intervention research: Cultural respon- siveness versus resource provision. Adv Nurs Sci 2000;22: $1-15$.

97. Chapman EN, Kaatz A, Carnes M. Physicians and implicit bias: How doctors may unwittingly perpetuate health care disparities. J Gen Intern Med 2013;28:1504-1510.

98. Phelan JC, Link BG. Is racism a fundamental cause of inequalities in health? Annu Rev Sociol 2015;41:311-330.

Address correspondence to: Juanita J. Chinn, PhD

Eunice Kennedy Shriver National Institute of Child Health and Human Development 6710 B Rockledge Drive, MSC 7002

Bethesda, MD 20982

USA

E-mail: juanita.chinn@nih.gov 